[RADIOCARbon, Vol. 26, No. 1, 1984, P 149-151]

\title{
RADIOCARBON-A DIRECT CALCULATION OF THE PERIOD OF THE GRAND TREND
}

\author{
ISRAEL CARMI, ZIV SIRKES, and MORDECKAI MAGARITZ
}

\author{
Department of Isotope Research \\ The Weizmann Institute of Science, 76100 Rehovot, Israel
}

A major collective effort was made to develop a data base for establishing the relationship between ${ }^{14} \mathrm{C}$ and calendric ages (Stuiver, 1982). The early "cosmic schwung" fit between the two ages (Suess, 1970a, p 310) and the 10,350 yr period of the grand trend (Suess, 1970b, p 596) have recently been replaced by the period of $12,100 \mathrm{yr}$ (Suess, 1980). The period of the grand trend was estimated by correlating the data with an a priori postulated sine function (Suess, 1970, p 596), or more recently a polynomial fit of the sixth degree was used (Klein et al, 1982). In the detrended data, periods (wiggles) of between $2400 \mathrm{yr}$ and $104 \mathrm{yr}$ were identified by conventional time series analysis. This approach could not be used to estimate the period of the grand trend, because the time series includes less than one cycle, whereas several cycles are required in order to get a meaningful result.

The prospect of extending the time series back several thousand years in order to complete at least one cycle of the grand trend, is not very good, as older woods suitable for dendrochronologic and ${ }^{14} \mathrm{C}$ dating are hard to find. Furthermore, if a sample is found, the necessary determination of its age by both methods is difficult and time consuming.

A new method of time series analysis, the Maximum Entropy Spectral Analysis (MESA) (Ulrych \& Bishop, 1975), offers many advantages over conventional approaches. One of these is the ability to identify long periods using relatively short time series. We report on the use of MESA to identify periods in the ${ }^{14} \mathrm{C}$ time series including the period of the grand trend, making no a priori assumptions.

We used the time series published by Suess (1978), which includes 449 data points. Since the time series is not equally spaced, as required by MESA, we averaged the data over each century, weighting the data points according to their errors. The gap between 5965 and 5402 BC could not be resolved by this procedure and the data prior to $5400 \mathrm{BC}$ were omitted. To complete the time series between $5400 \mathrm{BC}$ and $\mathrm{AD} 1300$, three data points were inserted by linear interpolation. The averaged time series contains 67 data points. Figure 1 displays the original and modified time series.

For the calculation we applied a program of MESA based on Barrodale and Erickson (1980a,b) and used a filter length of 26, determined by Akaike's Final Prediction Error (FPE) criterion (Ulrych \& Bishop, 1975). Figure 2 displays the relative power density spectrum of the averaged time series. Since the time step is $100 \mathrm{yr}$, no periods of $<200 \mathrm{yr}$ were detected. Periods $>200 \mathrm{yr}$, found by Fourier Analysis (Suess, 1980) are 202 yr, 308 yr, $498 \mathrm{yr}, 930 \mathrm{yr}$, and $2400 \mathrm{yr}$. Using MESA, without detrending and without making any $a$ priori assumptions, we reproduce all of the above periods $>200 \mathrm{yr}$, except that we obtain a period of $700 \mathrm{yr}$ instead of $308 \mathrm{yr}$. 
Furthermore, we get a very prominent peak at 13,200 yr, representing a direct determination of the period of the grand trend.

After having determined the period of the grand trend by MESA, we calculated its amplitude and phase by a non-linear least square fit on the original time series. The grand trend can be approximated by

$$
\Delta \mathrm{AGE}=440+490 \cos (2 \pi \mathrm{AGE} / 13,200+2.744)
$$

where $\triangle \mathrm{AGE}$ is the difference between calendric and ${ }^{14} \mathrm{C}$ ages. Accepting the grand trend to be a cyclic phenomenon, the calendric age of samples can be calculated by several successive iterations of the formula:

$$
\mathrm{AGE}_{\mathrm{n}+1}={ }^{14} \mathrm{CAGE}+440+490 \cos \left(2 \pi \mathrm{AGE}_{\mathrm{n}} / 13,200+2.744\right)
$$

using

$$
\mathrm{AGE}_{0}={ }^{14} \mathrm{C} \text { AGE. }
$$

\section{REFERENCES}

Barrodale, I and Erickson, R E, 1980a, Algorithms for least-squares linear prediction and maximum entropy spectral analysis-Part I: Theory: Geophysics, v 45, p 420432. spectral analysis-Part II: Fortran program: Geophysics, v 45, p 433-446. dates: Tables based on the consensus data of the Workshop on Calibrating the Radiocarbon Time Scale: Radiocarbon, v 24, p 103-150.

Stuiver, M, 1982, A high-precision calibration of the AD radiocarbon time scale: Radiocarbon, v 24, p 1-26.

Suess, H E, 1970a, Bristlecone pine calibration of the radiocarbon time scale $5300 \mathrm{BC}$ to the present, in Olsson, I U, ed, Radiocarbon variations and absolute chronology, Internatl radiocarbon conf, 7th, Proc: Stockholm, Almqvist \& Wiksell-Gebers Forlag AB, p 303-313.

$1970 \mathrm{~b}$, The three causes of the secular carbon-14 fluctuations, their amplitudes and time constants, in Olsson, I U, ed, Radiocarbon variations and absolute chronology, Internatl radiocarbon conf, 7th, Proc: Stockholm, Almqvist \& WiksellGebers Forlag AB, p 595-606.

1978, La Jolla measurements of radiocarbon in tree-ring dated wood: Radiocarbon, v 20, p 1-18.

1980, The radiocarbon record in tree rings of the last 8000 years, in Stuiver Minze and Kra, Renee, eds, Internatl radiocarbon conf, 10th, Proc: Radiocarbon, v 22, no. 2, p 200-209.

Ulrych, T J and Bishop, T N, 1975, Maximum entropy spectral analysis and autoregressive decomposition: Rev Geophys Space Physics, v 13, p 183-200. 


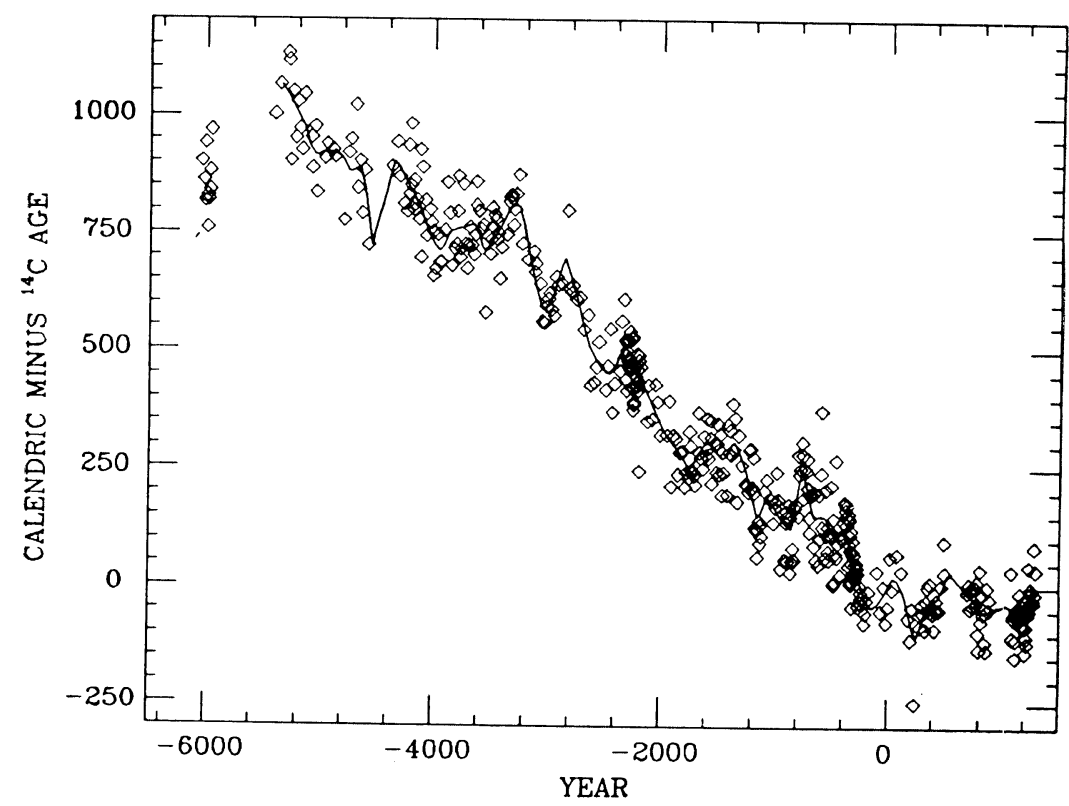

Fig 1. Time series of $\triangle \mathrm{AGE}$ (Suess, 1978)_diamonds Average values for consecutive centuries_full line

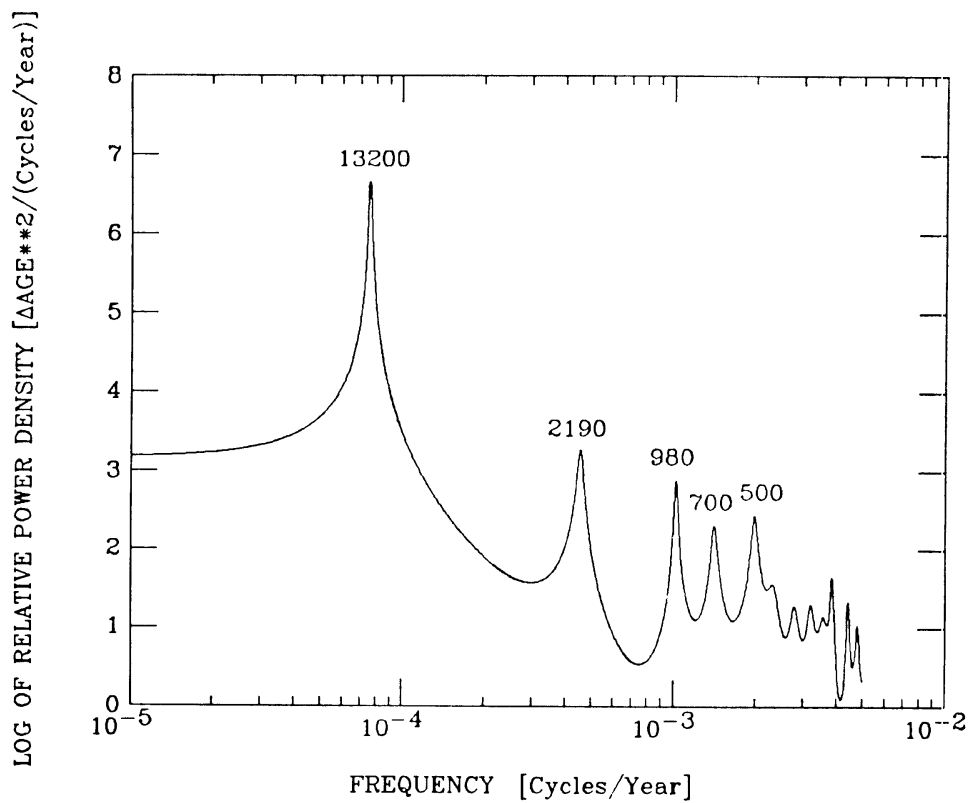

Fig 2. MESA relative power density spectrum of the averaged time series 